\title{
O EMPODERAMENTO DAS MULHERES SOROPOSITIVAS COMO CONCRETIZAÇÃO DA CIDADANIA FEMININA NO BRASIL
}

\author{
Karoline Veiga França ${ }^{1}$ \\ Maria Claudia Crespo Brauner ${ }^{2}$
}

\section{RESUMO}

O presente estudo, apoiado no método lógico-dedutivo de pesquisa bibliográfica, propõe uma reflexão crítica no que tange às mulheres soropositivas enquanto grupo de risco no Brasil. Esta ideia, embora já tenha sido superada pela ciência, ainda persiste no inconsciente coletivo, continuando a ser percebida no cotidiano dos brasileiros como fator de intolerância e preconceito, os quais dividem os cidadãos entre sãos e doentes. $\mathrm{O}$ objetivo da pesquisa é apresentar estratégias para que as mulheres soropositivas conquistem o seu empoderamento, a fim de exercerem plenamente a sua cidadania, construindo uma sociedade na qual impere a justiça social.

Palavras-chave: Mulheres Soropositivas. Direito à saúde. Empoderamento das Mulheres. Cidadania. Justiça Social.

\section{THE EMPOWERMENT OF SEROPOSITIVE WOMEN AS FEMININE CITIZENSHIP CONCRETISATION IN BRAZIL}

\begin{abstract}
This study, based on the logical-deductive method of bibliographical research, proposes a critical analysis about women as a group at risk in Brazil. This idea, although it has already been overcome by Science, it still exists in the collective unconscious and continues to be perceived in daily life of Brazilian people as an intolerance and prejudice factor, which divides the citizens between healthy and sick. The main goal of this reasearch is to present the ways seropositive women can get their empowerment, in order to exercise their citizenship in full, building a society in which the social justice prevails.
\end{abstract}

Keywords: Seropositive Women. Right to Health. Empowerment of Women. Citizenship. Social Justice.

\section{INTRODUÇÃO}

\footnotetext{
${ }^{1}$ Mestranda em Direito e Justiça Social na Universidade Federal do Rio Grande - FURG. Graduada em Direito pela Universidade Anhanguera - Rio Grande. Especialista em Direito Público pela Verbo Jurídico. Mestre em Letras pela Universidade Católica de Pelotas. Graduada em Letras pela Universidade Estadual do Maranhão.

${ }^{2}$ Professora da Universidade Federal do Rio Grande - FURG, Doutora em Direito pela Universidade de Rennes, na França, Pós-doutorado na Universidade de Montréal, no Canadá e Pesquisadora do CNPQ.
} 
Mesmo antes de nascerem, todas as pessoas já estão sujeitas ao poder do Estado e às suas normas, como se depreende do art. $2^{\circ}$ do Código Civil. No entanto, a plenitude do Estado de Direito só é possível com a participação efetiva de seus cidadãos, o que, por sua vez, pressupõe o conhecimento e o reconhecimento das normas que regem o ordenamento jurídico.

Nessa toada, a questão da soropositividade tem ocupado um espaço considerável de discussão no cenário mundial. Desde o início, na década de 1980, quando diagnosticados os primeiros casos de infecção pelo vírus HIV, mais precisamente nos Estados Unidos, as pessoas acometidas por tal doença têm enfrentado toda sorte de juízos de valor e preconceitos a respeito. Inicialmente, atribuía-se tal doença a "grupos de risco", que seriam compostos essencialmente por homossexuais masculinos e heterossexuais promíscuos. Depois, novos casos foram surgindo e com eles, mudanças em relação ao perfil do doente, destacando-se os hemofílicos que recebiam doação de sangue, os usuários de drogas, os estrangeiros, enfim, todos eles pertencentes a algum grupo vítima de discriminação.

Atualmente, a ideia de grupos de risco já foi superada pela ciência, embora ainda persista no inconsciente coletivo. E, mesmo sabendo-se que a síndrome atinge diferentes faixas etárias, classes sociais e orientações sexuais, ela continua percebida no cotidiano dos brasileiros como fator de intolerância e preconceito que dividem os cidadãos entre sãos e doentes. Dentre as categorias que vem sendo discriminadas encontram-se os idosos, os adolescentes e as mulheres.

O presente estudo teórico volta-se para as mulheres enquanto grupo de risco no Brasil, tendo como escopo promover uma reflexão a partir da apresentação de estratégias através das quais as mulheres soropositivas possam conquistar o seu empoderamento como forma de concretização do direito à saúde física e psíquica. Desta feita, tais mulheres podem vencer o preconceito e exercer plenamente a sua cidadania. A proposta investigativa está baseada no método lógico-dedutivo de pesquisa bibliográfica, promovendo uma reflexão em torno da interdisciplinaridade do tema, lançando mão de contribuições do Direito e da Saúde, com destaque às políticas públicas existentes.

Para tal, compõe-se de cinco itens. No primeiro, faz-se um panorama sobre o assunto a ser abordado. No segundo, traça-se um percurso por pontos relacionados à $A I D S$, às mulheres soropositivas, bem como à estratégia do empoderamento, o preconceito, a estigmatização e a questão do silêncio. $\mathrm{O}$ terceiro item faz uma discussão sobre a importância 
dos grupos de apoio frente ao combate à $A I D S$. O quarto item, por sua vez, traz a reflexões finais acerca deste trabalho. O quinto, apresenta as referências.

A escolha do tema prende-se à ausência da promoção de saúde mental das mulheres soropositivas em razão do preconceito. Outro contributo à seleção da temática em projeção é a observância de que o empoderamento poderá refletir, de forma positiva, na sociedade.

Com base na Constituição Federal cabe ao Estado assegurar que o direito fundamental à saúde, seja física ou mental, alcance a todos, sem qualquer tipo de distinção. Como um direito social condicionador da vida humana, dele derivam outros direitos, a saber: à vida, à liberdade, dentre outros, os quais constroem a dignidade da pessoa humana, e da justiça social. Espera-se que o referido estudo possa contribuir para a inclusão social das mulheres, ajudando a combater o preconceito do qual são vítimas em virtude de sua maior vulnerabilidade social.

\section{AIDS, MULHERES SOROPOSITIVAS: ESTATÉgIAS PARA SUPERAR O PRECONCEITO}

Desde os primeiros casos de $\operatorname{AIDS}^{3}$, que datam da década de 80, nos Estados Unidos, seus portadores têm enfrentado toda sorte de juízo de valor. Inicialmente, atribuía-se tal doença a "grupos de risco". Assim sendo, o HIV só atingia os homossexuais masculinos e heterossexuais promíscuos. Depois, novos casos foram surgindo e com eles, mudanças em relação ao perfil do doente: hemofílicos que recebiam doação de sangue, usuários de drogas, os estrangeiros, enfim, todos eles pertencentes a algum grupo vítima de discriminação.

Hodiernamente, a ideia de grupos de risco já foi superada pela ciência, embora essa categorização inicial ainda persista no inconsciente coletivo. E, mesmo sabendo-se que a síndrome atinge diferentes faixas etárias, classes sociais e condições sexuais, ela está cada vez mais impregnada no cotidiano dos brasileiros por meio da intolerância e preconceito que insistem em manter a divisão dos cidadãos entre os que "vivem no reino dos sãos e no reino dos doentes" (SONTAG, 2007, p. 11).

\footnotetext{
${ }^{3}$ SONTAG (2007) não faz distinção entre AIDS e HIV, portanto, este trabalho também não o faz. A autora concentra-se nos usos da doença como figura ou metáfora, não na doença em si. Sua preocupação está no âmbito linguístico, pois tem a finalidade de lutar por uma sociedade livre de preconceitos, na qual seja imperioso respeito às diferenças.
} 
A AIDS é considerada a epidemia do século. Por esta razão, tem atraído a atenção de vários setores da sociedade desde sua descoberta, e na seara jurídica não poderia ser diferente, onde tem sido alvo de grandes polêmicas, especialmente quando os princípios do Estado Democrático de Direito Brasileiro e os fundamentos das convenções internacionais vão de encontro com o preconceito sofrido por parte dos soropositivos.

\subsection{O preconceito e a estigmatização}

Susan Sontag, na obra "Doença como metáfora, AIDS e suas metáforas" (2007) investigou as metáforas existentes em doenças como a tuberculose, o câncer, a sífilis, a cólera e a AIDS. A autora afirma que é impossível pensar sem metáforas, porém é possível e necessário evitar as que estigmatizam. Ao fazer um contraponto entre as metáforas do câncer e da AIDS, Sontag ressalta que no primeiro, o doente é considerado uma vítima de "traição do próprio corpo" enquanto que na segunda, ele é um irresponsável, um delinquente. Desta maneira, a morte social precede a morte física, fomentando as metáforas que imputam significado à AIDS: "grupos de risco", "peste gay”, “doença estrangeira”, "pena de morte”.

Contudo, de todas as metáforas concernentes à AIDS, a considerada mais urgente para Sontag, quanto à extinção, é a militar, norteadora do campo da medicina, haja vista ter consequências mais perigosas, tanto por proporcionar "uma justificativa persuasiva para o autoritarismo" quanto à "repressão violenta por parte do Estado", fatos que contribuem para a rotulação da doença e, por conseguinte, do doente. Tais conceitos militares definiram o conceito de doença como um "invasor do corpo", um inimigo que deve ser eliminado. Neste sentido, combate-se o inimigo (a doença) com as armas do preconceito, afinal, as metáforas militares "provocam uma mobilização excessiva, uma representação exagerada e dão uma contribuição de peso para o processo de excomunhão e estigmatização do doente".

Voltando-se para o contexto feminino, a convivência com a síndrome torna-se uma experiência ainda mais dotada de dificuldades, uma vez que é irrefutável a sua vulnerabilidade em relação aos homens, seja por fatores biológicos, seja por fatores sociais. A exposição à violência e rótulos na sociedade conduz a mulher soropositiva por um caminho repleto de rejeição e exclusão social, o qual interferirá, sobremaneira, negativamente em suas vidas. 


\subsection{A questão do silêncio}

Com efeito, o preconceito e estigma experimentados pelas mulheres soropositivas ocasionam o silêncio como um mecanismo de defesa. Tal silêncio encontra suas raízes em assuntos relacionados à sexualidade, área bastante censurada na sociedade. Assim, a vulnerabilidade das soropositivas começa pela sua condição de mulher, silenciadas historicamente nas sociedades patriarcais as quais sustentam as desigualdades entre sexos. Sontag $(2007$, p.97) ao se referir às grandes epidemias mundiais, panorama em que se situa a $A I D S$, menciona a "culpa pecaminosa" que lhe é atribuída, reveladora deste silêncio.

Diferentemente do que parece, o silêncio das mulheres soropositivas não exprime um sentido de querer calar-se. Na verdade, representa o choro, o grito, o não reconhecimento. Orlandi (2007, p.13) afirma que o imaginário da sociedade destinou um lugar subalterno para o silêncio, o qual diz respeito a uma dimensão do não dito, porém, repleto de significação, é um procedimento com conotação política.

Isto posto, a mulher soropositiva vivencia a "cidadania mais onerosa" a que se refere Sontag (2007, p.11) quando da clássica divisão das pessoas vivas em sãs e doentes. As do segundo grupo submetem-se a uma redução na sua cidadania, uma perda efetiva de direitos, pois não é mais considerada útil para o desenvolvimento da sociedade e constitui, nesta condição de "doente" uma "comunidade de párias" (SONTAG, 2007, p. 97).

Há cerca de três décadas do aparecimento da $A I D S$, as pessoas têm tido conhecimento a seu respeito, tanto quanto às suas causas, consequências e modos de evitá-la. À vista disso, assim como o câncer ultrapassou o estigma de ser uma doença terrível e prenúncio de uma morte dolorosa, a AIDS caminha para um futuro em que se reverterá a uma patologia crônica. Enquanto este dia não chega, cabe àqueles que enfrentam a sua discriminação lutarem por uma sociedade efetivamente livre de injustiças e preconceitos, na qual vigore o respeito à dignidade humana.

\subsection{A estratégia do empoderamento}

Embora emergente, o termo empoderamento tem alcançado um lugar de destaque em debates acadêmicos e sociais nas últimas décadas. Iório (2002, p. 21) explica que não há um consenso quanto à sua procedência, se originário do movimento negro estadunidense do início da década de 60 ou dos movimentos feministas. Todavia, foi com este grupo que o 
empoderamento se desenvolveu tanto em nível teórico como instrumento de intervenção na realidade (IÓRIO, 2002, p. 21), do qual pode-se obter poder tanto positiva quanto negativamente.

À luz das palavras da autora, as primeiras conceitualizações sobre empoderamento manifestam-se com o movimento Women In Development (Mulheres no Desenvolvimento) com a percepção de empoderamento enquanto "poder sobre". Neste compasso, quem detinha o poder deveria ser desprovido em prol das mulheres empoderadas, pois a estratégia do empoderamento consistia no rompimento com a situação de dominação, as mulheres passariam a conquistar espaço nas estruturas econômicas e políticas da sociedade e, dessa forma, vir a participar do processo de desenvolvimento (IÓRIO, 2002, p.22). Após, outras conceitualizações foram tomando forma, a saber, a de Foucault, que propõe o poder como algo inerente às relações, trazendo a resistência como uma forma de poder.

Transportando tal raciocínio para um cenário democrático é relevante a criação de novas leis que favoreçam a luta dos excluídos e desempoderados. Todavia, é preciso ir além, mais ativamente, como afirma Iório:

\begin{abstract}
(...) É importante a promoção e implementação de processos participativos na gestão das políticas. Os governos devem assegurar canais para que os grupos e pessoas vivendo na pobreza possam fazer parte de instâncias de definição, implantação e monitoramento de políticas mais gerais (como orçamento participativo, conselhos de políticas sociais, segurança alimentar, previdência, conselhos de saúde, educação) e também dentro de programas de combate à pobreza e à exclusão (mas não somente nestes espaços). A participação é um elemento constitutivo das estratégias de empoderamento. (IÓRIO, 2002, p.29)
\end{abstract}

Para isso, a autora defende a descentralização de governos centrais a fim de fornecer "uma maior participação de grupos sociais no nível local e, nesse sentido, atender melhor às necessidades dos excluídos" (IÓRIO, 2002, p.30). Não é demais relembrar que empoderamento e descentralização são cosias distintas. Dessa maneira, correlacioná-los de forma a obter sucesso dependerá do contexto, bem como do objeto em discussão, etnia, gênero ou religião.

\title{
3. CIDADANIA E DIREITOS FUNDAMENTAIS
}

Positivado na Constituição Federal de 1988, a vida é o direito fundamental do qual decorrem todos os demais, estando, por conseguinte, vinculado a uma visão de total proteção. 
Não se resume apenas ao direito de viver, mas de ter uma existência digna, com direito de ter um piso mínimo de dignidade.

Nestes termos, o direito à vida está aliado ao conceito de bem-estar social e individual, tanto no que tange ao princípio da dignidade da pessoa humana, alicerce do ordenamento jurídico brasileiro, quanto à manutenção da vida por meio do acesso à saúde. Nesta toada, mister se faz a concretização das condições de existência mínima, para que o cidadão possa, de fato, usufruir de uma vida digna $\left(\mathrm{CF}\right.$, art. $1^{\circ}$, III). E é por meio dos direitos sociais (educação, saúde, alimentação, trabalho, moradia, transporte, lazer, segurança, previdência social, proteção à maternidade e à infância, assistência aos desamparados) que a dignidade da pessoa humana pode ser viabilizada.

$\mathrm{Na}$ esteira desse raciocínio, o Estado deve desenvolver políticas públicas para que o acesso a tais direitos aconteça universal e igualitariamente. Na lição de Canotilho (2000, p.385), "os Direitos Sociais têm a função de não discriminação, assegurando que o Estado trate seus cidadãos como fundamentais iguais".

A Declaração Universal dos Direitos do Homem consagra a dignidade da pessoa humana e igualdade, base para uma sociedade justa. A Constituição Federal de 1988, por sua vez, afirma em seu Preâmbulo que o Estado Democrático deve "assegurar o exercício dos direitos sociais e individuais, a liberdade, a segurança, o bem-estar, o desenvolvimento, a igualdade e a justiça, como valores supremos de uma sociedade fraterna, pluralista e sem preconceitos...".

$\mathrm{Na}$ seção dos Princípios Fundamentais, o artigo $1^{\circ}$, III, assevera que um dos fundamentos do Estado Democrático de Direito é a dignidade da pessoa humana. $\mathrm{O}$ artigo $3^{\circ}$, IV, afirma que são objetivos fundamentais da República Federativa do Brasil promover o bem de todos, sem preconceitos de origem, raça, sexo, cor, idade e quaisquer outras formas de discriminação. Também, o artigo $5^{\circ}$ que aborda o título Direitos e Garantias Individuais", reafirma a questão da igualdade e não-discriminação em seu caput, garantindo indenização por dano material, moral ou a imagem quando da violação dos bens jurídicos tutelados.

Outrossim, é importante mencionar algumas leis federais que visam garantir apoio aos soropositivos, a saber a Lei $n^{\circ} 9.313 / 1996$, a qual dispõe sobre a distribuição gratuita de medicamentos aos portadores do HIV e doentes de AIDS; e a Lei $\mathrm{n}^{\circ} 12.984 / 2014$, que define o crime de discriminação dos portadores do vírus da imunodeficiência humana $(H I V)$ e doentes de Aids. 


\subsection{0 direito à saúde}

O direito à saúde está amplamente expresso na Constituição Federal de 1988. Enquanto direito fundamental, encontra-se no art. $5^{\circ}, \S 1^{\circ}$. Na função de direito social, artigo $6^{\text {o }}$; como parte integrante da Seguridade Social, art. 194, com financiamento direto ou indireto pela sociedade, através de recursos oriundos dos orçamentos da União, dos Estados, do Distrito Federal e Municípios (art. 195, I, II e III), bem como outras fontes (art. 198, § $1^{\circ}$ ).

A Organização Mundial de Saúde (OMS) conceitua saúde como "o estado de completo bem-estar físico, mental e social e não apenas a ausência de doença ou de qualquer afecção". Em âmbito nacional, a Lei 8.080/90 acata tal conceito:

\footnotetext{
Art. $3^{\circ}$ - Os níveis de saúde expressam a organização social e econômica do País, tendo a saúde como determinantes e condicionantes, entre outros, a alimentação, a moradia, o saneamento básico, o meio ambiente, o trabalho, a renda, a educação, a atividade física, o transporte, o lazer e o acesso aos bens e serviços essenciais.

Parágrafo único - Dizem respeito também à saúde as ações que, por força do disposto no artigo anterior, se destinam a garantir às pessoas e à coletividade condições de bem-estar físico, mental e social.
}

Neste aspecto, conceituar saúde implica na observância de um contexto de qualidade de vida. Em esfera constitucional, A Carta Magna admite a saúde como direito de todos e dever do Estado:

Art. 196 - A saúde é direito de todos e dever do Estado, garantido mediante políticas sociais e econômicas que visem à redução do risco de doença e de outros agravos e ao acesso universal e igualitário às ações e serviços para sua promoção, proteção e recuperação.

Apesar de o Brasil ainda precisar avançar no enfrentamento da patologia, há o reconhecimento dos resultados positivos no que tange às questões ligadas à prevenção e ao tratamento da doença, devendo ainda, buscar a redução do número de pessoas que têm AIDS, sem saber.

\subsection{Políticas Públicas existentes}

No que tange às políticas públicas é reconhecido que "nos últimos anos as ações voltadas para as mulheres se fortaleceram, pautadas, principalmente, sob o olhar da 
vulnerabilidade, na possibilidade de não infecção infantil decorrente de gestação, parto e aleitamento materno e pela pressão social na busca da obediência aos direitos humanos e melhoria das condições de sobrevivência com o HIV. Todavia, ainda são consideradas insuficientes pois as ações deveriam considerar as iniquidades desse grupo populacional que apresenta particularidades que o torna mais vulnerável”. (Vidal et all. 2009, p. 172)

Parker \& Galvão (1996, p.7) reconhecem que a "vulnerabilidade das mulheres frente ao HIV/AIDS e o impacto da epidemia nas suas vidas" são "colocados como uma questão secundária, cercada, quase sempre, pelo silêncio e descaso tradicionalmente associados com a sexualidade e a saúde femininas". Este cenário de exclusão tem levado ao agravamento da feminização da $A I D S$, revelando uma insuficiência de políticas públicas destinadas às mulheres soropositivas no país, não total, porém significativa. Isso se deve às ações moldadas pelos modelos hegemônicos centralizadores, burocratizados e patriarcais.

Corroborando, ainda, do mesmo raciocínio, os referidos autores evidenciam que “talvez (...) em nenhum lugar a omissão da responsabilidade em relação às mulheres e à AIDS tenha se feito tão profunda como no campo das políticas públicas e dos programas oficiais associados ao controle da AIDS no Brasil e aos serviços de saúde da mulher”.

As políticas públicas prejudicam sua legitimidade quando desconsideram os diferentes níveis de vulnerabilidade da população. Entram nessa seara, a questão das desigualdades sociais e econômicas que acometem o Brasil.

No que tange à transmissão vertical do HIV, o Ministério da Saúde (2001, p.20) afirma que:

(...) os melhores resultados com relação ao controle da infecção materna e, consequentemente, os melhores resultados de profilaxia da transmissão vertical desse vírus", razão pela qual "o teste anti-HIV deverá ser oferecido a todas as gestantes, independente de sua situação de risco para o $H I V$, tão logo ela inicie seu pré-natal", tendo, no entanto, a preocupação de que o teste seja "sempre voluntário e confidencial.

Para tal garantia, os gestores de políticas públicas de saúde devem assegurar principalmente a qualificação dos profissionais de assistência obstétrica, o que é uma tarefa bastante árdua.

Outro fator preponderante é promover o reconhecimento das condições de maior vulnerabilidade da mulher, quer sejam biológicas, sociais, culturais, ou decorrentes de relações de gênero, ressalta-se a "necessidade de intervir mais amplamente no fortalecimento 
das mulheres e na superação das desigualdades sociais, econômicas e culturais entre homens e mulheres", como forma de promover a saúde sexual e reprodutiva de mulheres e de seus/suas parceiras. (Vidal et all, 2009, p. 173)

\subsection{Perfil das mulheres soropositivas}

É sabido que a infecção pelo HIV foi, prioritariamente, detectada na população masculina. Por isso, as normas referentes à sua prevenção, diagnóstico e assistência estão voltadas para este grupo, havendo, posteriormente, apenas uma adaptação às mulheres.

Parker \& Galvão (1996, p.10) declaram que as primeiras campanhas de prevenção na mídia visando especificamente às mulheres datam de 1994, "com o intuito de promover o uso do preservativo masculino por parte das mulheres sexualmente ativas". Tais campanhas não consideravam as construções socioculturais, bem como as hierarquias de poder entre homens e mulheres no que tange, dentre outras coisas, a negociação do preservativo, dando início, assim, à questão da vulnerabilidade feminina ao $H I V$. Movimentos feministas, ONGs e demais movimentos ativistas passaram a ter um papel fundamental na luta contra a feminização da $A I D S$.

Nesse sentido, as relações de poder entre homens e mulheres, sejam culturais, sociais ou econômicas aceleraram o processo de feminização da AIDS. Villela (2005, p.68) afirma que a exclusão, discriminação e opressão relacionadas ao gênero, à etnia, à faixa etária e ao modo de exercer a sexualidade também interferem no grau de saúde das populações, porque dificultam o acesso a meios garantidores da prevenção e cuidado, causando agravos.

Guimarães (2001, p. 31), por sua vez, denuncia a mudança do perfil da epidemia, através da incidência de casos em mulheres, relatando que o aumento de mulheres infectadas tornou-se significativo em razão das práticas sexuais com homens portadores do vírus. Esta afirmação vai de encontro com o discurso de que apenas as mulheres promíscuas e usuárias de drogas são populações de "alto risco" ao vírus.

Segundo o Boletim Epidemiológico de $2016^{4}$, de 1980 a junho de 2016, foram notificados 842.710 casos de $A I D S$ no Brasil. O país tem registrado, anualmente, uma média de 41,1 mil novos casos da doença nos últimos cinco anos.

\footnotetext{
${ }^{4}$ Boletim Epidemiológico HIV/Aids do Departamento de Vigilância, Prevenção e Controle das Infecções Sexualmente Transmissíveis, do HIV/Aids e das Hepatites Virais (DIAHV), da Secretaria de Vigilância em
} 
No que se refere aos sexos, a taxa de detecção de AIDS apresenta importantes diferenças regionais. Nas regiões Sudeste e Centro-Oeste, há um predomínio de homens em comparação com as demais regiões. Em 2015, a razão de sexos é, em média, de 23,5 casos em homens para cada 10 casos em mulheres. Nas regiões Norte e Nordeste, em 2015, há 21 casos em homens para cada 10 casos em mulheres. Na região Sul, 12 homens para cada 10 mulheres.

Outro dado pertinente do Boletim diz respeito à maior concentração dos casos da epidemia quanto à idade: indivíduos entre 25 e 39 anos para ambos os sexos. Entre os homens, essa faixa etária corresponde a 53,0\%, enquanto que, entre as mulheres, é de 49,4\% do total de casos registrados de 1980 a junho de 2016.

Voltando-se para a taxa de deteç̧ão de $A I D S$ no quesito etnia/cor da pele e sexo no período de 2006 a 2015, observou-se a não existência de diferença nas proporções branca, amarela, parda e indígena, apenas nos pretos. Importante mencionar que a proporção das mulheres é superior à dos homens. Em 2015, 11,9\% dos casos de AIDS eram de mulheres pretas, enquanto que 10,2\% eram de homens pretos. Nesse mesmo ano, as proporções das raças branca, amarela, parda e indígena foram de 43,1\%, 0,4\%, 45,6\% e 0,3\%, respectivamente, no total dos casos.

Quanto às mulheres gestantes, a taxa de detecção com HIV vem aumentando nos últimos dez anos. Enquanto que, em 2006, a taxa observada foi de 2,1 casos/mil nascidos vivos, em 2015 passou para 2,7 em 2015, indicando um aumento de 28,6\%. Esta tendência é observada em todas regiões do país, salvo para a região Sudeste, a qual permaneceu estável, com taxa de 2,2 casos/mil nascidos vivos em 2006 e 2,1 em 2015. Por outro lado, as regiões Norte e Nordeste apresentaram maiores aumentos na taxa: ambas apresentavam taxa de 1,2 em 2006, passando para 2,9 e 2,0 casos/mil nascidos vivos em 2015, respectivamente. Em 2015, a região Sul apresentou a maior taxa de detecção (5,9 casos/mil nascidos vivos).

Entre as Unidades da Federação, o Rio Grande do Sul, Santa Catarina, Amazonas, Roraima, Amapá e Rio de Janeiro apresentaram taxa de detecção de HIV em gestantes superior à taxa nacional em 2015, com 10,1; 5,6; 4,0; 3,9; 3,6 e 2,9 casos/mil nascidos vivos, respectivamente. Os estados do Amazonas, Roraima, Amapá, Alagoas, Maranhão e Mato

Saúde (SVS), do Ministério da Saúde (MS), o qual é publicado anualmente contendo informações e análises a respeito dos casos de HIV/AIDS no Brasil. 
Grosso do Sul, por seu turno, apresentaram tendência de aumento nas taxas de detecção nos últimos dez anos.

Comparando-se as capitais, São Paulo, Brasília, Goiânia, Belo Horizonte e João Pessoa apresentaram taxa de detecção inferior à taxa nacional, em 2015, com 2,6; 1,5; 1,5; 1,5 e 0,8; respectivamente. Porto Alegre é a capital com a maior taxa de detecção de 2015, com 22,9 casos/mil nascidos vivos, sendo 8,4 vezes maior que a taxa nacional e 2,3 vezes maior que a taxa do estado do Rio Grande do Sul, com 10,1 casos/mil nascidos vivos.

Ainda acerca das mulheres gestantes, desde o ano 2000, observa-se que a faixa etária que apresenta o maior número de casos de gestantes infectadas com HIV é entre 20 e 24 anos, com um percentual de $28,6 \%$.

Quanto à raça/cor da pele autodeclarada, há um predomínio da cor parda, seguida da branca; em 2015, com 45,9\% e 38,1\% dos casos, respectivamente. As gestantes pretas correspondem a $15,0 \%$ nesse mesmo ano.

A partir das informações acima referidas é possível identificar que mesmo levando em consideração as disparidades regionais, no que concerne o contágio da doença por homens e mulheres, continua havendo um crescimento da doença. E que, há aumento progressivo de casos de HIV em mulheres jovens e gestantes, mostrando a relação com gênero, etnia e faixa etária. Esse fator é bastante preocupante justificando a perspectiva apresentada no presente artigo.

\subsection{AIDS e doença mental}

A estigmatização da $A I D S$ causa um impacto significativo na saúde mental dos doentes. Depressão, isolamento social, uso de drogas, bebidas alcóolicas, suicídio, são apenas alguns dos transtornos mentais que tornam os doentes mais vulneráveis, os quais começam a aparecer a partir do diagnóstico, repercutindo negativamente na evolução da doença.

Desta maneira, as pessoas passam a ter uma visão distorcida do risco de infecção, fora a dificuldade de adotar medidas preventivas, bem como de acesso ao tratamento. Portanto, oferecer tratamento no campo mental para soropositivos é elemento indissociável para combater a doença, e, consequentemente, o preconceito, afinal, este é o principal desafio a ser vencido para que haja a promoção da saúde e qualidade de vida das mulheres soropositivas. 
Assim sendo, o atendimento aos pacientes deve ser diferenciado. Uma alternativa eficaz para o atendimento diferenciado seria a intervenção psicoterapêutica para as soropositivas. Tal tratamento combateria a estigmatização a partir da perspectiva que têm de si mesmas, substituindo a visão de vítima pela de ser humano que está doente e não que se resume à doença, reafirmando a sua cidadania.

\subsection{AIDS e doença física}

Assim como na saúde mental, a estigmatização da AIDS também causa danos à saúde física dos doentes. É sabido que, para melhores resultados quando do diagnóstico e assistência, exames regulares são essenciais. No caso das mulheres soropositivas, tornam-se imperativos, especialmente devido à sua saúde ginecológica ${ }^{5}$ apresentam maior risco de problemas ginecológicos, tais como infecções por fungos vaginais, doença inflamatória pélvica e problemas cervicais.

Ao descobrir-se infectada, uma mulher deve passar por um exame ginecológico assim que passar por uma consulta. Se tudo estiver normal, o melhor é repetir o teste depois de seis meses. Após estas duas consultas, um exame ginecológico anual é suficiente. Caso não se apresente normal, sendo algum problema detectado pelo médico, exames ginecológicos mais frequentes serão normalmente necessários. Problemas ginecológicos como sangramentos anormais no ciclo menstrual da mulher, ou sangramentos incomuns, dor, inchaço, ou prurido em ou em torno de sua vagina ou abaixo do abdome, também devem ser analisados o quanto antes.

Além do acesso aos exames e ao tratamento adequado, as mulheres devem receber uma atenção que promova o seu empoderamento, valorizando a expressão da sua autonomia corporal e sua autoestima, de modo a promover o exercício pleno de sua cidadania. Para tanto, os grupos de apoio cumprem uma função importante.

\subsection{Grupos de apoio}

\footnotetext{
${ }^{5}$ Informação disponível no site Soropositivo.org. Há vida com $H I V$.
} 
O desenvolvimento de projetos e ações no Brasil a fim de difundir informações sobre a AIDS, tanto quanto à prevenção como no tratamento físico têm sido desenvolvidos com o fito de criar abordagens para o seu enfrentamento. Entretanto, o aspecto mental, que, como citado anteriormente, tem grande impacto na vida das soropositivas - e de viés duplo: da sociedade para elas e delas para a sociedade - não tem recebido a merecida atenção.

Nesse sentido, os grupos de apoio que trabalham com o intuito de superar obstáculos no que tange aos soropositivos, além de atuar junto às áreas da saúde que cuidam das condições materiais, voltadas para a saúde física, devem esmerar-se no reestabelecimento dos vínculos desfeitos em razão do preconceito nas diferentes esferas do convívio social.

O GIV (Grupo de Incentivo à Vida) ${ }^{6}$ é um exemplo de grupo que luta pelos direitos de pessoas soropositivas. Suas missões vão desde propiciar melhores alternativas de qualidade de vida, tanto no âmbito social como da saúde física e mental, a toda pessoa vivendo com HIV/AIDS; promover a integração social das pessoas vivendo com HIV/AIDS entre si e, seus familiares, amigos e profissionais multidisciplinares no âmbito nacional e internacional; a troca de experiência de vida, tendo como base a ajuda mútua; desenvolver trabalhos promocionais e assistenciais em favor das pessoas vivendo com HIV/AIDS, seus familiares e amigos (as), e população em geral até meios para desenvolver trabalhos de assistência social, psicoterapia, cursos, palestras, terapias alternativas reconhecidas entre outras formas de apoio.

O referido grupo de apoio conta também com projetos em andamento como o Saúde Mental e Psicologia, que trata das questões emocionais e tem como objetivo ser um grupo de convivência para pessoas que vivem e/ou convivem com o HIV/Aids; e o Toque de Mulher ${ }^{7}$, espaço voltado ao universo feminino, no qual elas podem resgatar laços de relações e convivência, fazer novas amizades, buscando promover o conhecimento dos direitos da mulher enquanto cidadãs soropositivas, estimulando a atuação do controle social em busca de melhores serviços de saúde, acompanhamento no tratamento da doença e fortalecendo as mulheres com apoio psicológico inerente ao enfrentamento da doença.

Com base no exposto, os grupos de apoio tornam-se verdadeiros aliados ao empoderamento de soropositivas, haja vista representarem um espaço de trocas de experiências, onde elas conseguem deixar de ser invisíveis e passam ter forças para lutar por sua dignidade, seu espaço na sociedade. Dessa maneira, tais grupos dão continuidade ao

\footnotetext{
${ }^{6}$ http://www.giv.org.br/

${ }^{7} \mathrm{http}$ ://www.giv.org.br/projetos/toquedemulher/
} 
tratamento físico pelo qual elas perpassam. Em outras palavras, tais experiências servem para promover o empoderamento, que se constitui em uma forma de promoção da cidadania das mulheres.

\section{CONCLUSÃO}

A título de reflexões finais, observou-se que o direito social fundamental à saúde deve ser atendido de maneira abrangente não apenas no seu sentido físico, proporcionado acesso à tratamentos e medicamentos, mas também, promovendo o bem-estar e a saúde mental dos cidadãos, haja vista a Constituição Federal assegurar que o direito fundamental à saúde, seja física ou psíquica, alcança a todos, sem qualquer tipo de distinção.

No que tange ao atendimento das mulheres soropositivas, no Brasil, embora o tratamento de prevenção e de combate à $A I D S$ tenha melhorado sobremaneira desde a descoberta da patologia até os dias atuais, ainda é precário o atendimento no campo da saúde mental, área bastante afetada pela síndrome.

A preocupação com a condição da mulher se justifica face aos rótulos que ela carrega pela sua condição de mulher na sociedade ainda fortemente patriarcal. Uma boa solução seria assegurar a intervenção psicoterapêutica para as soropositivas, como forma de superar a estigmatização de que são vítimas. Assim, elas poderiam encontrar um caminho que lhes aponte o sentido do tratamento, bem como perceberem que podem viver suas vidas plenamente.

O empoderamento das mulheres soropositivas repercutirá no exercício pleno de sua cidadania por meio da participação nos espaços públicos, de autoaceitação com relação à condição de mulher soropositiva.

A maioria dos problemas atribuídos à AIDS estão relacionados ao preconceito. É preciso desconstrui-lo em prol da construção de uma sociedade justa. Os estigmas só serão abandonados quando o doente passar a ser ter sua individualidade plenamente respeitada, com a dignidade restaurada.

Afinal, uma sociedade justa é aquela na qual os direitos humanos são respeitados, onde seus cidadãos caminham juntos em prol de construir uma sociedade moral e política alicerçada na igualdade de direitos e na solidariedade coletiva. Trata-se de construir caminhos para diminuir a invisibilidade dos excluídos tão invisíveis. 


\section{REFERÊNCIAS}

BARROSO, Luís Barroso. Judicialização, ativismo social e legitimidade democrática. 2008.Disponívelem: <http://www.direitofranca.br/direitonovo/FKCEimagens/file/ArtigoBarro so para Selecao.pdf> Acesso: 25 nov. 2015.

BOLETIM EPIDEMOLÔGICO HIV/AIDS, 2016. Disponível em: < http://www.aids.gov.br/sites/default/files/anexos/publicacao/2016/59291/boletim $20161 \mathrm{pdf}$ _16375.pdf >. Acesso em 15 maio 2017.

BRASIL, Constituição (1988). Constituição da República Federativa do Brasil de 1988. Disponível em: <http://www.planalto.gov.br/ccivil_03/Constituicao/Constituicao.htm>. Acesso: 10 nov. 2015.

BRASIL, Ministério da Saúde. Igualdade de gênero e HIV/AIDS: uma política por construir. Rede feminista de saúde. Brasília (DF). MS, 2003. Disponível em: <www.saude.gov.br/bvs >. Acesso: 25 out. 2015.

CANOTILHO, Joaquim José Gomes. Direito Constitucional e Teoria da Constituição. 4. ed. Coimbra: Almedina, 2000.

GRUPO DE INCENTIVO À VIDA. Disponível em:< http://www.giv.org.br/ > Acesso: 01 dez. 2015.

GUIMARÃES, K. Nas raízes do silêncio: a representação cultural da sexualidade feminina e a prevenção do HIV/Aids. In: PARKER, R.; GALVÃ̃O, J. (Org.). Quebrando o silêncio: mulheres e Aids no Brasil. Rio de Janeiro: Relume-Dumará, 1996.

GUIMARÃES, C. Aids no feminino: por que a cada dia mais mulheres contraem Aids no Brasil? Rio de Janeiro: Ed. UFRJ, 2001.

IORIO, Cecília. Algumas considerações sobre estratégias de empoderamento e de direitos. In: ROMANO, Jorge \& ANTUNES, Marta (Orgs.). Empoderamento e direitos no combate à pobreza. Rio de Janeiro: ActionAid Brasil, 2002.

MINISTÉRIO DA SAÚDE, 2001. Recomendações para Profilaxia da Transmissão Materno-infantil do HIV e Terapia Anti-retroviral em Gestantes. Brasília: Coordenação Nacional de DST/AIDS, Ministério da Saúde.

ORGANIZACIÓN MUNDIAL DE LA SALUD. Documentos básicos. 26.ed. Ginebra: OMS,1976.

ORLANDI, E.P. As formas do silêncio. No movimento dos sentidos. $6^{a}$ ed. Campinas: Ed. Da Unicamp, 1993. 
PARKER, R.; GALVÃO, J. Quebrando o silêncio: mulheres e AIDS no Brasil. Rio de Janeiro: Relume-Dumará, ABIA, IMS/UERJ, 1996.

PORTAL BRASIL. Disponível em < http://www.brasil.gov.br/saude/2015/07/onu-aponta-obrasil-como-referencia-mundial-no-controle-da-aids>. Acesso: 23 nov. 2015.

SONTAG, Susan. Doença como metáfora, AIDS e suas metáforas. Trad. Rubens Figueiredo; Paulo Henriques Britto. São Paulo: Companhia das Letras, 2007.

SOROPOSITIVO. ORG. Há vida com HIV. Disponível em: https://soropositivo.org/2016/04/30/mulheres-hiv-outras-dsts-e-aids/. Acesso: 15 maio 2017.

VILLELA, W. V. Vulnerabilidade, sexualidade e subjetividade: sobre a face feminina da aids. In: CARVALHO, M. E. G.; CARVALHAES, F. F.; CORDEIRO, R. P. (Org.). Cultura e subjetividade em tempos de aids. Londrina: Associação Londrinense Interdisciplinar de Aids, 2005.

VIDAL, E. C. F., et all. Políticas públicas para pessoas com HIV: discutindo direitos sexuais e reprodutivos. Rev. Rene. Fortaleza, v. 10, n. 2, p. 166-174, abr./jun.2009. 